\title{
The Cost Efficiency of Construction Industry in Taiwan
}

\author{
Ren-Jye Dzeng and Jih-Shong $\mathrm{Wu}^{*}$
}

Department of Civil Engineering, National Chiao-Tung University, Taiwan (R.O.C.). 1001 University Rd., Hsinchu, Taiwan (R.O.C.)

\begin{abstract}
The construction industry is high amount of cash flow which creates high financial leverage. To thrive in this industry under the pressure of global market competitions and the impact of profit margin compression, determining a higher cost efficiency module becomes essential for construction operations. In this study, 27 Taiwan OTC construction companies are examined using the Stochastic Frontier Analysis during 2002-2009. By using the regression model and the translog cost function to evaluate the cost inefficiency, equipment cost, and firm scale. The results of this study suggested that: (i) the cost efficiency showed that there was still a room for improvement, (ii) reduce higher labor capacity can use subcontracting, (iii) larger firms may be more cost efficiency, and (iv) increase the cost efficiency by reducing equipment costs. It is hoped that through the findings of this study, we could attract the attention of government departments to improve their development strategies for the construction industry; at the same time, these study findings could also suggest construction companies to improve their management strategy and improve their cost efficiency by reducing their operating expenses and risks.
\end{abstract}

Keywords: Cost efficiency, construction, stochastic frontier analysis (SFA).

\section{INTRODUCTION}

The construction industry is high density labor force and collaboration with different upstream and downstream industries. A construction often requires manpower, machinery, equipment, materials and transportation. Harrison [1] proposed construction industry is heterogeneous and complex nature of its output; almost every project in construction is unique. It is exceedingly difficult to find a uniform measure of the quality of construction projects.

This collaboration between different fields creates development and growth in related industries. Due to these factors, the construction industry is high amount of cash flow which creates high financial leverage. Due to the globalization of markets, more and more countries are joining the World Trade Organization (WTO); Taiwan, too, has joined WTO in 2002. However, by joining WTO, Taiwan's construction industry, composed of mainly small and medium sized enterprises, is now competing against the world's market, including China's market. Now Taiwan's construction industry faces international construction firms that have advanced technologies, better management systems, and more funds. Some companies even compete in Taiwan's construction market with cheaper labor. Furthermore, the world economic crisis has also been affecting Taiwan's construction industry, reducing the profit rate and resulting in bankruptcy of many construction companies. In order to manage and survive through this hard time, the construction industry

\footnotetext{
*Address correspondence to this author at the Department of Civil Engineering, National Chiao-Tung University, Taiwan (R.O.C.). 13F., No.28, Ln. 167, Zhongzheng Rd., Zhonghe Dist., New Taipei City 235, Taiwan (R.O.C.); Tel: 886-937429090; Fax: 886-2-22422588;

E-mail: bill.wu26@msa.hinet.net
}

must improve their cost efficiency to acquire better contracts and profits.

In recent years, many efficiency measurements captured a great deal of attention. The research has seen rapid growth in the number of studies applying frontier efficiency methods [2]. Thore et al. [3] used the Data Envelopment Analysis (DEA) and productivity method to analyze the relationship between operation efficiency and productivity of Americanbrand computer companies. The study showed that companies such as Apple, Compaq, and Seagate all have high amount of efficiency; however, companies with lesser efficiency are increasing their sales and market share. The reason is because these companies strategize to sacrifice their efficiency in productivity to focus more on increasing sales. Karlafits [4] used the DEA to evaluate the efficiency and effectiveness of urban transit systems. The results allowed the administrators to organize their bus service efficiency according to their ranking systems to help evaluate the system's progress to achieve the public service goal. The results were also able to help monitor and improve the transportation management system. Yoshidaa and Fujimoto [5] used the DEA to evaluate the efficiency of Japanese airports, and concluded that the local airports have lesser efficiency compared to international airports. Tong and Chan [6] aimed to empirically examine the changes in production efficiencies of China's township and village enterprises between 1988 and 1993 with particular reference to the spatial disparity of these changes. This study was able to conclude that the coastal regions of China have higher productivity efficiency than those of the inland regions. $\mathrm{Li}$ and $\mathrm{Hu}$ [7] used the Stochastic Frontier Analysis (SFA) to establish a theory model, evaluating small and medium sized enterprises in Taiwan and China, and the relationship between local technology 
efficiency and manufacture locations. The results suggested that higher technology efficiency can attract oversea investors, and can also reduce the impact of high salary and setup cost. Li et al. [8] used the SFA to evaluate the relationship between the technology efficiency of banks and the government's share in these banks. Three different types of banks were evaluated; national banks, private banks, and mixture banks which the relationship between government shareholding and the rate of nonperforming loans. The conclusion of this research is that national banks can benefit and improve their technology efficiency by adapting methods used by mixture banks.

The concept of cost efficiency can be traced back to Farrell [9], who originated many of the ideas underlying DEA [10]. Vennet [11] used the stochastic frontier cost function to evaluate the 492 cases of mergers and acquisitions of credit institutions in the European Commission during 1988-1992. The results showed that higher cost efficiency was significant only when credit institutions with similar scale of success merged; the act of acquisitioning another bank does not create an economics of scale. Cummins and $\mathrm{Zi}$ [12] used two different methods to evaluate the efficiency of life insurance companies. One of the methods was the econometric estimation of average response methods, using translog cost function to determine the scale efficiency of these companies; the other method was the DEA method. The research indicated that smaller companies showed an increasing return to scale while the bigger companies showed a decreasing return to scale. Camanho and Dyson [10] used the DEA method to evaluate the cost efficiency of subsidiary banks. The results obtained in the case study showed that the DEA models can provide robust estimates of cost efficiency even in situations of price uncertainty. Manlagňit [13] examined the cost efficiency of Philippine commercial banks using stochastic frontier analysis and specifically incorporating risk and asset quality measures in the estimation. The results showed substantial inefficiencies among domestic banks and that risk and asset quality affect the efficiency of banks. HernándezSancho and Sala-Garrido [14] used the DEA method to evaluate the efficiency of wastewater treatment plants, aiming to improve the sewage recycling process. The research indicated that maintenance cost and waste management cost were the most important factors that affect the efficiency of wastewater treatment plants. Puig-Junoy [15] used the DEA method to evaluate the cost efficiency of 94 acute care hospitals approved by the Ministry of Health in Spain. The research was aimed to improve the cost efficiency of the hospitals by privatization of the hospitals and implementing management policies.

There have been several researches of the efficiency measurement in construction industry. Chau and Wang [16] used the DEA method to evaluate the productivity efficiency of construction firms in Hong Kong .The results showed: (i) larger firms could produce more efficiency than smaller firms, (ii) companies used mechanization to improve the growth efficiency, and (iii) companies used subcontracting and outsourcing to improve productivity efficiency. Chau et al. [17] used the DEA method to evaluate productivity effi- ciency of construction firms in Hong Kong. The results showed: (i) larger firms were more efficient, but the scale effects were exhausted up to a certain size; (ii) professional outsourcing produced better productivity efficiency; and (iii) more capital intensive firms tended to have lower productive over time. Sueyoshi and Goto [18] used the DEA method to evaluate the construction industry policies in Japan. The research indicated that Japanese construction companies have high amount of labors, and the industry were the main support of the local economy. For example, the construction industry in Japan made 5.1\% of the Gross Domestic Product in year 2005. The research also showed that in order to avoid bankruptcy in the construction industry, the Japanese government supplied road construction contracts to support major construction companies; however, during the period of this research, it showed that the government supports were not sufficient to help the construction companies' worsening financial performance. Chiang et al. [19] used the inputoutput analysis and DEA method to evaluate the construction department's financial performances in Japan. The research was aimed to improve the government policies and reduce risk factors. El-Mashaleh et al. [20] used the DEA method to evaluate the safety efficiency of every contractor aiming to transform inefficient contractors into high efficiency contractors.

Due to the project uniqueness and high risk factors of the construction industry, the measurement of efficiency weren't as simple as measuring input and output in manufacturing or service industries. The data which were needed to measure efficiency in the construction industry include labor force, machinery, material, etc.... These data were hard to acquire in mass, and were also hard to converge for analysis purposes. This is why there are few researches related to construction industry cost efficiency.

In this study, the cost efficiency of construction companies was evaluated by using the data from their financial statement. The purpose of the study was to: (1) evaluate the cost efficiency of the construction industry in Taiwan; and (2) analyze the important factors that affect cost efficiency, and produce a strategy to improve these factors. It is hoped that through the results of this study, the conclusion could be reached to reduce companies' operating expenses and risks, and which could also suggest the Taiwan government to shape construction development strategies.

\section{METHODOLOGY}

\subsection{Efficiency Measurement}

The words "productivity" and "efficiency" are often used when measuring the performance of companies or organizations; however, these words actually have two distinctive differences. The productivity is referred to the ratio between product output and input [21].

$\mathrm{P}=\mathrm{O} / \mathrm{I}$

where $P$ is productivity; $O$ is output; and $I$ is input.

The efficiency is a goal oriented method to determine the best scenario while having the goal of using lowest input or 
reaching highest output. The discussion of efficiency measurement began with Farrell [9], who drew upon the work of Debreu [22] and Koopmans [23] to define a simple measure of firm efficiency that could account for multiple input. Farrell [9] proposed that the efficiency of a firm consists of two components: (i) technical efficiency, which reflects the ability of a firm to obtain maximal output from a given set of input, and (ii) allocative efficiency, which reflects the ability of a firm to use the inputs in optimal proportions, given their respective prices and the production technology. These two measures are then combined to provide a measure of total economic efficiency.

Frontiers have been estimated using many different methods over the past 40 years. The piece-wise-linear convex hull approach to frontier estimation, proposed by Farrell [9], was considered by only a few authors in the two decades following Farrell's paper. Boles [24], Shephard [25] and Afriat [26] suggested mathematical programming methods that could achieve the task, but the method did not receive wide attention until the paper by Charnes, Cooper and Rhodes [27], in which the term Data Envelopment Analysis (DEA) was first used. Since then a large number of papers have appeared, which have extended and applied the DEA methodology [28].

The most common four methods of measuring efficiency are: (i) least-squares (LS) econometric model, (ii) total factor productivity (TFP) indices (Tornqvist/Fisher), (iii) data envelopment analysis (DEA), and (iv) stochastic frontiers (SF). The first two methods are most often applied to aggregate time-series data and provide measures of technical change and/or TFP. Both of these methods assume all firms are technically efficient. Methods 3 and 4, on the other hand, are most often applied to data on a sample of firms (at one point in time) and provide measures of relative efficiency among those firms. Hence these latter two methods do not assume that all firms are technically efficient [28].

Efficiency is generally measured using either DEA or stochastic frontier methods. Some of the advantages of stochastic frontiers over DEA are [28]:

- it accounts for noise, and

- it can be used to conduct conventional tests of hypotheses.

While some disadvantages are:

- the need to specify a distributional form for the inefficiency term, and

- the need to specify a functional form for the production function (or cost function, etc.).

Aigner and Chu [29] considered a Cobb-Douglas production frontier of the form [28]:

$\ln q_{i}=X_{i}^{\prime} \beta-u_{i} i=1,2, \ldots . I$

where $q_{i}$ represent the output of the $i$-th firm; $X^{\prime}{ }_{i}$ is a $(K \times$

$1)$ vector containing the logarithms of inputs; $\beta$ is a vector of unknown parameters; and $u_{i}$ is a non-negative random variable associated with technical inefficiency.

Aigner, Lovell and Schmidt [30] and Meeusen and van den Broeck [31] independently proposed the stochastic frontier production function model of the form $[28,32]$ :

$\ln q_{i}=X_{i}^{\prime} \beta+V_{i}-u_{i}$

which is identical to the model (2) except we have added a symmetric random error, $V_{i}$ to account for statistical noise.

Battese and Coelli [32] proposed a model for technical inefficiency effects in a stochastic frontier production function for panel data:

$Y_{i t}=\exp \left(X_{i t} \beta+V_{i t}-U_{i t}\right)$

where $Y_{i t}$ denotes the production at the $t$-th observation $(t=$ $1,2, \ldots, T)$ for the $i$-th firm $(i=1,2, \ldots, N) ; X_{i t}$ is a $(1 \times K)$ vector of values of known functions of inputs of production and other explanatory variables associated with the $i$-th firm at the $t$-th observation; $\beta$ is a $(K \times 1)$ vector of unknown parameters to be estimated; the $V_{i t} \mathrm{~s}$ are assumed to be $\operatorname{iidN}\left(0, \sigma_{v}^{2}\right)$ random errors, independently distributed of the $U_{i t} \mathrm{~s}$; the $U_{i t} \mathrm{~s}$ are non-negative random variables, associated with technical inefficiency of production, which are assumed to be independently distributed, such that $U_{i t}$ is obtained by truncation (at zero) of the normal distribution with mean $Z_{i t} \delta$, and variance $\sigma^{2} ; Z_{i t}$ is a $(1 \times m)$ vector of explanatory variables associated with technical inefficiency of production of firms over time; and $\delta$ is a $(m \times 1)$ vector of unknown coefficients.

The technical inefficiency effect $U_{i t}$ in the stochastic frontier model (4) could be specified in equation (5):

$U_{i t}=Z_{i t}+W_{i t}$

Where the random variable $W_{i t}$ is defined by the truncation of the normal distribution with zero mean and variance $\sigma^{2}$, such that the point of truncation is $-Z_{i t} \delta$ ie., $W_{i t} \geq-Z_{i t} \delta$. These assumptions are consistent with $U_{i t}$ being a non-negative truncation of the $N\left(Z_{i t} \delta, \sigma^{2}\right)$-distribution.

\subsection{Cost Function}

Mester [33], Cebenoyan et al. [34] and Allen and Rai [35] used the stochastic cost frontier methodology. Altunbas et al. [36] proposed the cost frontier was obtained by estimating a Fourier Flexible cost function with a composite error term, the sum of a two-sided error representing random fluctuations in cost and a one-sided positive error term representing inefficiency.

The single-equation stochastic cost function model can be given as:

$T C=T C\left(Q_{i}, P_{i}\right)+\varepsilon_{i}$ 
Where $T C$ is observed total cost, $Q_{i}$ is a vector of outputs (such as: net sale), and $P_{i}$ is an input price vector (such as: Price of Labor $P_{L}$ ). Following Aigner et al. [30], Altunbas et al. [36] assume that the error term of the cost function is:

$$
\varepsilon=u+v
$$

Where $u$ and $v$ are independently distributed. The $u$ is usually assumed to be distributed as half-normal, that is, a one-sided positive disturbance capturing the effects of inefficiency, and $v$ is assumed to be distributed as two-sided normal with zero mean and variance $\sigma^{2}$, capturing the effects of the statistical noise.

Due to the complexity of construction industry operations, the measurement of efficiency in this industry cannot be acquired with a simple input/output production function. The construction contracts are often unique projects with high risk and long duration. The labor force, machinery and material are not as easy to acquire comparing to manufacture or service industries; therefore, it is harder to acquire mass production data for the purpose of measuring cost efficiency.

The data in this study were acquired from financial statements of individual construction companies. The data mostly indicated the cost for each company to operate, instead of an input - output data sheet used in the manufacture industry. The study used the Stochastic Frontier Analysis and Cost Function Model to evaluate the cost efficiency of the Taiwan construction industry. The goal was to analyze the important factors which influenced the cost efficiency by comparing the cost efficiency index, and suggested a strategy to reduce the operating expenses and risks.

\section{DATA AND EMPIRICAL MODEL}

\subsection{Samples and Data Sources}

The sample of this study was from 54 listed OTC (overthe counter) companies. These 54 samples were then filtered again, removing companies which revenues were earned through estate, had $90 \%$ or lesser revenue through construction operations, or became bankrupt. After filtering, the study sample remains 27 construction companies. In average, $98.5 \%$ of these construction companies' revenue was acquired through construction operations. Out of these 27 companies, there were 216 operations samples; the sample period was 8 years apart from 2002 to 2009 . These samples were annual financial statements from each company which were publicly listed on The Taiwan Stock Exchange Inc. [37]. Because the general price-level changed in the 8 year period, this study used the consumer price index of year 2006 as base period for GDP deflator conversion.

\subsection{Variables}

The construction industry is composed of mass labor, machinery, and materials. In this study, the variables acquired from the financial statement are: (1) Output is Gross Output (net sale); and (2) Inputs are Total Cost (Cost of Goods Sold), Price of Capital, and Price of Labor.
The definitions of each variable are listed below; for statistic data please refer to Table $\mathbf{1}$.

- Gross Output $(Q)$ : The Gross Output is acquired from income statement - net sale.

- Total Cost (TC): The Total Cost is acquired from income statement - cost of goods sold which include fund cost, labor cost and capital cost.

- Capital $(K)$ : The Capital is acquired from the balance sheet - Net value of fixed assets which includes: (a) land, and (b) depreciable assets (such as: factory, mechanical equipment, transportation equipment, and office equipment, etc., but excluding the aforementioned depreciation).

- Labor Force $(L)$ : The Labor Force is acquired from the financial statement - number of employees.

- Price of Capital $\left(P_{K}\right)$ : The Price of Capital is determined by adding the interest expense from income statement with depreciation, divided by Capital (net value of fixed assets). The result shows the depreciation and interest expense each capital unit shares which is the Price of Capital. The formula: $P_{K}=($ deprecation + interest expense) / Capital.

- Price of Labor $\left(P_{L}\right)$ : The Price of Labor is determined by dividing Labor Costs from operating expense with the numbers of employee. The result shows the average labor expense for each employee which is the Price of Labor. The formula: $P_{L}=$ Labor Costs / Numbers of Employee.

- Company Attributes $\left(D_{i}\right)$ : Depending on the operation and income factors, this study separates the companies into two categories using two dummy variables where: (a) $D_{i}=0$ indicates that the company's operation include both civic and building construction, or only civil construction, and (b) $D_{i}=1$ indicates that the company's operation includes only building construction.

\subsection{Empirical Model}

This study was based on Battese and Coelli's Stochastic Frontier Analysis model in 1995 [32] and Altunbas's et al. cost frontier model in 2000 [36]. This study used these two methods to evaluate the relationship between cost inefficiency index and its variables which were equipment cost, firm scale, and company attributes. These three variables were applied to a simultaneous equation as external factors to determine their technical inefficiency effects $u_{i t}$. The empirical model was as follows:

$$
\begin{aligned}
& \ln \left(\frac{T C_{i t}}{P L_{i t}}\right)=\beta_{0}+\beta_{1} \ln \left(\frac{P_{K i t}}{P_{L i t}}\right)+\beta_{2} \ln Q_{i t}+\frac{1}{2} \beta_{3}\left[\ln \left(\frac{P_{K i t}}{P_{L i t}}\right)\right]^{2} \\
& +\frac{1}{2} \beta_{4}\left[\ln Q_{i t}\right]^{2}+\beta_{5}\left[\ln \left(\frac{P_{K i t}}{P_{L i t}}\right)\right]\left[\ln Q_{i t}\right]+v_{i t}+u_{i t} \\
& u_{i t}=\delta_{0}+\delta_{1} \ln E_{i t}+\delta_{2} \ln Q_{i t}+\delta_{3} D_{i}+\varepsilon_{i t}
\end{aligned}
$$

where equation(8) is the Stochastic Frontier Cost Function, and equation(9) is the technical inefficiency effects. 
Table 1. Descriptive Statistics of Variables

\begin{tabular}{|c|c|c|c|c|c|}
\hline Variables & Samples & Mean & Standard Deviation & Minimum & Maximum \\
\hline cost of goods sold (US\$) & 216 & $130,367 \mathrm{k}$ & $130,721 \mathrm{k}$ & $99 \mathrm{k}$ & $568,815 \mathrm{k}$ \\
\hline fixed assets (US\$) & 216 & $32,667 \mathrm{k}$ & $47,478 \mathrm{k}$ & $21 \mathrm{k}$ & $274,540 \mathrm{k}$ \\
\hline depreciation (US\$) & 216 & $5,905 \mathrm{k}$ & $8,364 \mathrm{k}$ & $11 \mathrm{k}$ & $45,999 \mathrm{k}$ \\
\hline Labor Costs (US\$) & 216 & $6,639 \mathrm{k}$ & $7,975 \mathrm{k}$ & $351 \mathrm{k}$ & $39,517 \mathrm{k}$ \\
\hline Numbers of Employee & 216 & 234 & 292 & 12 & 1,532 \\
\hline equipment cost (US\$) & 216 & $5,371 \mathrm{k}$ & $10,224 \mathrm{k}$ & $0.07 \mathrm{k}$ & $47,220 \mathrm{k}$ \\
\hline
\end{tabular}

Note: $\mathrm{k}=\mathrm{US} \$ 1,000$

where: $i$ is company code; $t$ is time;

$T C_{i t}$ is the total cost of company $i$;

$P_{K i t}$ is the capital input factor price of company $i$;

$P_{L i t}$ is the labor input factor price of company $i$;

$Q_{i t}$ is the total output of company $i$, under the inefficiency model stands for firm scale;

$E_{i t}$ is the equipment cost of company $i$, which includes transportation equipment cost and mechanical equipment cost;

$v_{i t}$ is the random errors of company $i$ within the time period $t$. The $v_{i t}$ is independently and identically distributed normal random variables with zero means variances $\sigma_{v}^{2}$.

$u_{i t}$ is the inefficiency errors of company $i$, which would make within the time period $t$, and signifies the level of inefficiency. The $u_{i t}$ is independently and identically distributed half-normal random variables with scale parameter $\sigma_{u}^{2}$. That is, the probability density function of each $u_{i t}$ is a truncated version of a normal random variable having zero mean and variance $\sigma_{u}^{2}$;

$E_{i t}$ is the equipment cost of company $i$ within the period $t$

$D_{i}$ is the company attribute where $D_{i}=0$ represents a company which operates both civil and building construction, or only civil construction, and $D_{i}=1$ represents a company which focuses solely on building construction;

$\varepsilon_{i t}$ is a random errors and a nonnegative truncated normal distribution. Variables in this equation are $\sigma_{\varepsilon}^{2}, \varepsilon \geq-\delta Z$, $\delta=\left(\delta_{1}, \delta_{2}, \delta_{3}\right), Z=\left(\ln R_{i t}, \ln Q_{i t}, D_{i}\right)$.
The efficiency index of Company $i$ within the $t$ period is $\exp \left(-u_{i t}\right)$; namely, the level of inefficiency $\left(u_{i t}\right)$ increases while the efficiency index decreases. The efficiency index $\exp \left(-u_{i t}\right)$ is a number between 0 and 1 ; the higher in value of this index means the more efficient the company $i$ is within the period $t$. The inefficiency index $\exp \left(u_{i t}\right)$ is the reciprocal of efficiency index $\exp \left(-u_{i t}\right)$ and is within the range of 1 and $+\infty$. The higher in value of the inefficiency index means the less efficient the company $i$ is within the period $t$. This empirical model exams the relationship between input and output, and also analyzes the technical change that affects these relations; with this information and data, the model was able to focus on studying the inefficiency factors.

\section{RESULTS AND DISCUSSION}

This study evaluates the performance of 27 construction companies from 2002 to 2009 . This study analysis the data with Frontier 4.1 [28], the results are shown in Table 2 with its maximum likelihood estimation, and shown in Fig. (1). The result of average cost efficiency 0.76 is discovered and the discussions are as follows.

(1) The average cost efficiency of Taiwan construction industry is 0.76 . The result shows that there is still a room for improvement. The key factors in this study result a $24 \%$ increase in cost; in other words, $24 \%$ of cost was wasted.

(2) The relative factor price between capital and labor $\left(\frac{P_{K i t}}{P_{L i t}}\right)$ shows a significant level of negative correlation (Table 2-1, t-ratio= -3.8034). In other words, the relative factor price is inversely proportional to the cost; if the relative factor price decreases, it shows an increase in the cost. The suggestions are as follows:

- Construction companies should reduce the purchase of unnecessary total fixed assets, such as land and equipment, to reduce pressure from fund procurement. 
- Due to the high demand in funding required for construction projects, most of the construction contracts are required to finance their projects through bank and/or other financial organizations. Financing and loans allow the companies to accept contracts using lesser percentage of their own equity fund. Although financing results in extra interest fee, it allows the company to have more available funds to contract more projects; therefore, increasing their cost efficiency.

The construction industry is considered a high risk industry in Taiwan; therefore, banks are more conservative towards giving loans and credits to this industry. The amount of funding in construction companies is the assurance whether they have the ability to finish contracts smoothly. The funding is also the major factor whether these companies would earn a profit. In addition, in the construction industry, the performance bond and warranty bond on the contract are often acquired through over-drafts from the company's bank account. Property development companies could often secure a loan using the land or house they are building on as collateral, but construction companies do not have these options due to their business focus; therefore, construction companies often face this problem while acquiring a loan, or end up paying a higher interest for their loans. In this study, the suggestion to the government would be giving the construction industry the assistance they need in funding.

- When an excellent rated construction company acquires a general public construction contract, it is suggested that government departments subsidize the interest rates on their loans, reducing the risks for the bank.

- When an excellent rated construction company acquires a major public construction contract, it is suggested that government departments coordinate with financial organizations to organize a larger loan with lower interest rates.

- Private projects also need the government to coordinate with financial organizations to acquire a larger loan and lower interest rates. Moreover, the loans should be earmarked funds to reduce risks and to increase the desire of financial organizations to invest.

- For the companies who introduce new technology and new construction methods, it is suggested that government departments subsidize the interest rates of their loan, and also coordinate with financial organizations to grant special rates.

Furthermore, due to the uniqueness in scale, difficulty, and construction method in each individual project, the number of labor force needed is hard to estimate prior to acquiring the project. In addition, the processes in construction project are not repetitive like they are in manufacture operations; therefore, the product technology efficiency of the construction industry is lower in comparison. This is the major reason why construction projects are unique in many ways. Chau and Wang [16] proposed construction companies could not predict future demand and work loads precisely.
On the other hand, labor inputs were deployed in a much more flexible way in the construction industry. The use of casual daily-wage labor and labor only sub-contractors can minimize idle labor under uncertain workloads. This study also indicated that a mass number of labor force was required in construction projects. The management strategy suggested was to use automatic machinery and subcontracting to lower the cost of labor.

(3) The study shows a significant level of positive correlation (table 2-1, t-ratio $=9.6178$ ) between the cost and gross output (net sales). Furthermore, the study also shows a significant level of negative correlation (Table 2-2, t-ratio $=-3.5395$ ) between gross output and cost inefficiency $\left(u_{i t}\right)$. This signifies that firms with larger scale have higher cost efficiency. Larger firms have a competition advantage from their better management systems, so they can acquire more contracts and therefore reduce the operating expense. The empirical results suggest that larger firms are more efficient. Chau et al. [17] proposed larger firms were likely to be more technologically advanced and systematically managed, had lower resource and finance costs due to better marketing and bargaining power, faced fewer competitors, and were in a better position to diversify risks. But the scale effects were exhausted up to a certain size.

(4) This study indicates that there is a significant level of positive correlation between the cost inefficiency and equipment (Table 2-2, t-ratio $=1.8771$ ), meaning the investment in equipment (both machinery equipment and transportation equipment) reduces cost efficiency. In other words, construction companies should aim to reduce the investments in machinery equipment and transportation equipment. This study result supports the suggestion of Chau's et al. research in 2005 [17]. Chau et al. [17] suggested that investing in capital (plant and machinery) would lead to problems of managing the utilization of resources, and thus lower efficiency. The other suggestion concluded in this study is subcontracting; more specifically, subcontracting when unique construction methods or large amount of machineries are required. Subcontracting under these special circumstances could reduce the investment in machinery and transportation equipments; therefore, also reducing the procurement, maintenance, operating, idle and depreciation costs.

(5) The study indicates that there is a significant level of negative correlation (table 2-2, t-ratio $=-3.1515$ ) between cost inefficiency and the company's attribute. The company that focuses solely on building constructions has a higher cost efficiency than those who operate both civil and building constructions, or only civil construction. This is because the building constructions are often private projects which have a higher profit margin than public works. On the other hand, the public works often come with stricter company requirements and the project bidding most likely goes to the lowest bidder. In general, public works often have lower budgets and shorter dura- 
Table 2. Estimates of the translog cost frontier function

\begin{tabular}{|c|c|c|c|c|}
\hline Variable description & Coefficient & Estimate & Standard Error & t-ratio \\
\hline Constant in the cost frontier & $\beta_{0}$ & -14.7214 & 1.6297 & $-9.0334^{* * * *}$ \\
\hline $\ln \left(\frac{P_{K i t}}{P_{L i t}}\right)$ & $\beta_{1}$ & -0.6370 & 0.1675 & $-3.8034^{* * * *}$ \\
\hline $\ln Q_{i t}$ & $\beta_{2}$ & 1.8332 & 0.1906 & $9.6178^{* * * *}$ \\
\hline $\ln \left(\frac{P_{K i t}}{P_{L i t}}\right)^{2}$ & $\beta_{3}$ & -0.0449 & 0.0170 & $-2.8976^{* * * *}$ \\
\hline $\ln Q_{i t}^{2}$ & $\beta_{4}$ & -0.0392 & 0.0137 & $-2.8542^{* * * *}$ \\
\hline $\ln \left(\frac{P_{K i t}}{P_{L i t}}\right) \times \ln Q_{i t}$ & $\beta_{5}$ & 0.0326 & 0.0140 & $2.3252^{* *}$ \\
\hline \multicolumn{5}{|c|}{ Table 2-2. Estimates of the cost inefficiency } \\
\hline Constant of cost inefficiency & $\delta_{0}$ & 10.2517 & 2.6810 & $3.8239^{* * * *}$ \\
\hline $\ln E_{i t}$ & $\delta_{1}$ & 0.1103 & 0.0588 & $1.8771^{*}$ \\
\hline $\ln Q_{i t}$ & $\delta_{2}$ & -0.8925 & 0.2521 & $-3.5395^{* * * *}$ \\
\hline$D_{i}$ & $\delta_{3}$ & -2.3646 & 0.7503 & $-3.1515^{* * * *}$ \\
\hline
\end{tabular}

Note: $1 . * * * * *$, and $*$ represent significance at the $1 \%, 5 \%$, and $10 \%$ levels, respectively.

2. Log likelihood function $=-75.3952$.

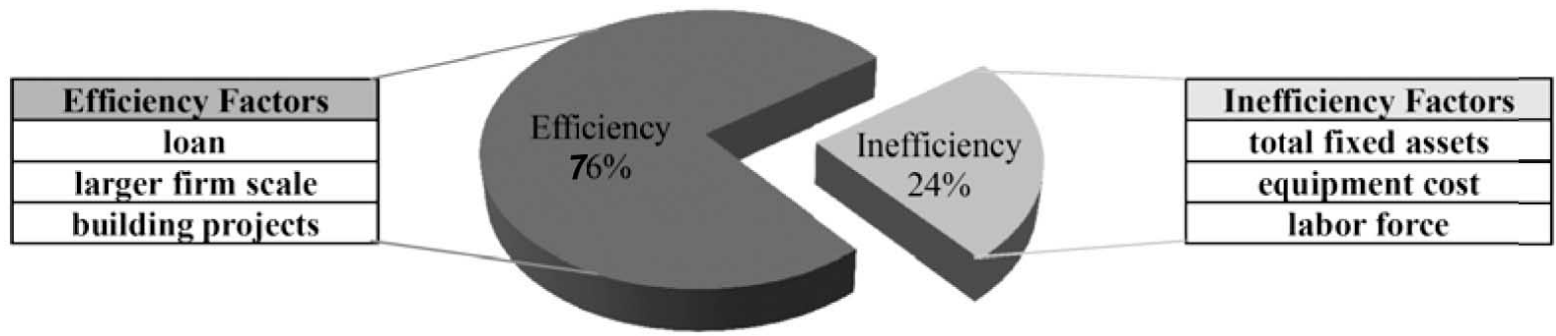

Fig. (1). The study results of the key factors.

tions. Lower bidding results in lower profit, and shorter duration results in higher risk. This is why the cost efficiency is lower. The suggestion to improve public works biddings are as follows.

- Public works biddings should have a reasonable budget and should avoid over-compressing the contractor's management fee and profit margin. If these changes were made, the construction company's risk could be reasonably reduced.

- Public works biddings should avoid using the lowest bidding method; instead, the "reasonable bidding" method should be introduced. The contract could be awarded to the second lowest bidder to avoid unnecessary destructive competition.
- Public works should allow a reasonable duration. A reasonable duration could be determined through professional engineering consultant companies and government departments should really consider using these standards instead. The current policy allows only an overcompressed duration which most construction companies cannot follow, resulting in penalty or fine.

- Government should encourage and invite construction companies with excellent ratings to enter government contract biddings, and honor these companies by subsidizing their loan interest rates.

This study calculates the average cost efficiency of all construction companies during the sample period (shown in 
Fig. (2)) with an average cost efficiency rate of 0.76. During the eight sample years, the lowest average cost efficiency was in year 2003, with a rate of $53.9 \%$. This research found that the reason of this low cost efficiency was due to the outbreak of SARS and the Iraq War, which both happened in 2003. The Taiwanese government reduced a huge amount of budget for major public works projects, thus lowering the willingness of companies to bid for contracts. In addition, Taiwan construction industry's contribution to 2003 GDP is $5.17 \%$ lower than its contribution to the 2004 GDP. Moreover, the $3.67 \%$ GDP in 2003 is lower than both the $5.26 \%$ GDP in 2002 and 6.19\% GDP in 2004 [38].

Moreover, the sample years do not have a big difference in their annual average cost efficiency; they all have an average cost efficiency of more or less 0.8 , with the exception of year 2003. This research signals that the Taiwan construction industry still has substantial room for operating efficiency improvements; there wasn't much change in the 8 sample years to signify improvements. The construction industry should be aware of this important message.

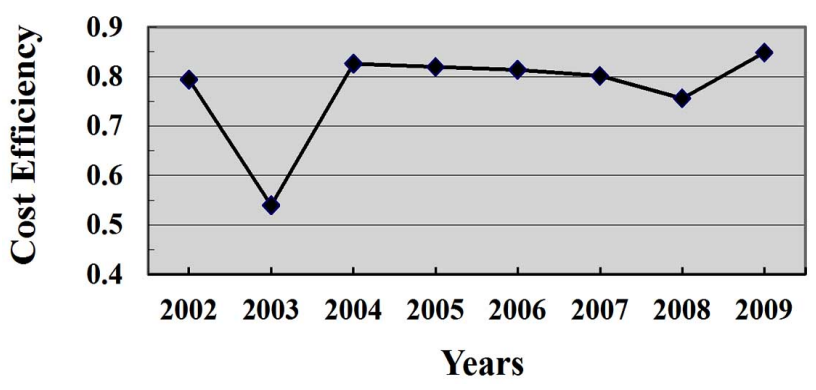

Fig. (2). The average cost efficiency of all construction firms.

\section{CONCLUSIONS}

The study examines the cost efficiency of construction industry in Taiwan; the study consists of 216 samples from 27 companies in an eight year sample period. The study uses Stochastic Frontier Cost Function to analyze the data and estimate the result with maximum likelihood estimation. The study data shows that the average cost efficiency rate is 0.76 , so most of the construction companies suffer from management inefficiency and still have a substantial room for improvement. Furthermore, while gathering research data, the study discovered that many large construction companies that focus on public works contract has gone bankrupted in the past few years. This is because most public works contracts in Taiwan are awarded to the lowest bidder; in order to acquire these contracts, construction companies often bid a destructive low price which is too low to even sustain their cost. These companies enter a vicious circle where they manage their business with high risk, high cost, but low profit; the operation efficiency generally decreases over each cycle, and finally results in bankruptcy.

The suggestions from this study to government departments are:

1) Government departments should coordinate with financial institutions to release a higher amount of loan with lower interest rates.
2) A reasonable project budget should be introduced to allow the contractors to have a reasonable management fee and profit, thus reducing their risks.

3) Government departments should avoid using the "lowest bidding" method to avoid unnecessary destructive competitions.

4) Government departments should honor a reasonable duration.

5) Government departments should encourage companies with excellent ratings to enter contract biddings; they could do so by introducing a preferential performance bond agreement and subsidization for the interest rates.

To improve the operation efficiency of the construction companies in Taiwan, the study result suggests the following:

a. Construction companies should strengthen their organization by moderating their scale of focus to achieve specialization, maximization, and self-improvements in technologies.

b. Construction companies should seek long-term subcontracting relationship with different field-speciation companies to avoid purchase of unnecessary equipment.

c. Construction companies should implement automatic machinery and subcontracting to reduce the cost and labor needs.

d. The funding in construction projects is suggested to be acquired from loans by financial institutes; this could avoid the company's funds to be locked into certain projects and allows more control of their funds. More usage of the company's capital reduces the management cost and gives the company more competitive edge; therefore, increasing the company's operation efficiency.

It is hoped that through the findings of this study, we could attract the attention of government departments to improve their development strategies for the construction industry; at the same time, these study findings could also suggest construction companies to improve their management strategy and improve their cost efficiency by reducing their operating expenses and risks.

\section{CONFLICT OF INTEREST}

Declared none.

\section{ACKNOWLEDGEMENT}

The authors appreciate the two expert referees and the editor for providing valuable suggestions for this paper.

\section{REFERENCES}

[1] P. Harrison, "Can measurement error explain the weakness of productivity growth in the Canadian construction industry", Int. Product. Monit., vol. 14, pp. 53-70, 2007.

[2] M. Eling, and M. Luhnen, "Efficiency in the international insurance industry: a cross-country comparison", J. Bank. Finance, vol. 34, no. 7, pp. 1497-1509, 2010.

[3] T. Sten, G. Kozmetsky, and F. Phillips, "DEA of financial statements data: the U.S. computer industry", J. Prod. Anal., vol. 5, pp. 229-248, 1994. 
[4] M. G. Karlaftis, "A DEA approach for evaluating the efficiency and effectiveness of urban transit systems", Eur. J. Oper. Res., vol. 152, pp. 354-364, 2004.

[5] Y. Yoshidaa, and H. Fujimoto, "Japanese-airport benchmarking with the DEA and endogenous-weight TFP methods: testing the criticism of overinvestment in Japanese regional airports", Transp. Res. Part E: Logist. Transp. Rev., vol. 40, no. 6, pp. 533-546, 2004.

[6] S. P. Tong, and H. L. Chan, "Disparity in production efficiency of China's TVES across regions: a stochastic frontier production function approach", Asia Pac. J. Manag., vol. 20, pp. 113-131, 2003.

[7] Y. Li, and J. L. Hu, "Technical efficiency and location choice of small and medium-sized enterprises", Small Bus. Econ., vol. 19, pp. 1-12, 2002.

[8] Y. Li, J. L. Hu, and Y. H. Chiu, "Ownership and production efficiency: evidence from Taiwanese banks", Serv. Ind. J., vol. 24, no. 4, pp. 129-148, 2004.

[9] D. J. Farrell, "The measurement of productive efficiency", J. $R$. Stat. Soc., vol. 120, pp. 253-281, 1957.

[10] A.S. Camanho, and R.G. Dyson, "Cost efficiency measurement with price uncertainty: a DEA application to bank branch assessments", Eur. J. Oper. Res., vol. 161, pp. 432-446, 2005.

[11] R. V. Vennet, "The effect of mergers and acquisitions on the efficiency and profitability of EC credit institutions", J. Bank. Finance, vol. 20, pp. 1531-1558, 1996

[12] J. D. Cummins, and H. Zi, "Comparison of Frontier Efficiency Methods: An Application to the U.S. Life Insurance Industry", $J$. Prod. Anal., vol. 10, pp. 131-152, 1998.

[13] M. C. V. Manlagňit, "Cost efficiency, determinants, and risk preferences in banking: a case of stochastic frontier analysis in the Philippines", J. Asian Econ., vol. 22, no. 1, pp. 23-35, 2011.

[14] F. Hernández-Sancho, and R. Sala-Garrido, "Technical efficiency and cost analysis in wastewater treatment processes: a DEA approach", Desalination, vol. 249, no. 1, pp. 230-234, 2009.

[15] J. Puig-Junoy, "Partitioning input cost efficiency into its allocative and technical components: an empirical DEA application to hospitals", Socio. Econ. Plan. Sci., vol. 34, pp. 199-218, 2000.

[16] K. W. Chau, and Y. S. Wang, "Factors Affecting the Productive Efficiency of Construction Firms in Hong Kong", CIB TG 23 International Conference, Hong Kong, 2003.

[17] K. W. Chau, S. W. Poon, Y. S. Wang, and L. L. Lu, "Technological progress and the productive efficiency of construction firms in Hong Kong”, J. Constrct. Res., vol. 6, no. 2, pp. 195-207, 2005.

[18] T. Sueyoshi, and M. Goto, "DEA-DA for bankruptcy-based performance assessment: misclassification analysis of Japanese construction industry", Eur. J. Oper. Res., vol. 199, pp. 576-594, 2009.

[19] Y.H. Chiang, E.W.L. Cheng, and B.S. Tang, "Examining repercussions of consumptions and inputs placed on the construction sector by use of I-O tables and DEA", Build. Environ., vol. 41, no. 1, pp. 1-11, 2006.

[20] M.S. El-Mashaleh, S.M. Rababeh, and K.H. Hyari, "Utilizing data envelopment analysis to benchmark safety performance of con- struction contractors", Int. J. Proj. Manage., vol. 28, pp. 61-67, 2010.

[21] Z. Griliches, "Issues in assessing the contribution of research and development to productivity growth", Bell. J. Econ., vol. 10, no. 1, pp. 92-116, 1979.

[22] G. Debreu, "The coefficient of resource utilization", Econometric, vol. 19, pp. 273-292, 1951.

[23] T.C. Koopmans, "An analysis of production as an efficient combination of activities, activity analysis of production and allocation, cowles commission for research in economics", Monograph, no. 13, Wiley: New York, 1951.

[24] J.N. Boles, "Efficiency Squared - Efficiency Computation of Efficiency Indexes", Proceedings of The 39th Annual Meeting of The Western Farm Economics Association, pp. 137-142, 1966.

[25] R.W. Shephard, Theory of Cost and Production Functions, Princeton University Press: Princeton, 1970.

[26] S. N. Afriat, "Efficiency estimation of production functions", Int. Econ. Rev., vol. 13, pp. 568-598, 1972.

[27] A. Chames, W.W. Cooper, and E. Rhodes, "Measuring the efficiency of decision making units", Eur. J. Oper. Res., vol. 2, pp. 429-444, 1978.

[28] T.J. Coelli, D.S.P. Rao, C.J. O'Donnell, and G.E. Battese, An Introduction to Efficiency and Productivity Analysis, 2nd ed., Spinger: New York, 2005.

[29] D. J. Aigner, and S.F. Chu, "On estimating the industry production function”, Am. Econ. Rev., vol. 58, pp. 826-839, 1968.

[30] D.J. Aigner, C.A.K. Lovell, and P. Schmidt, "Formulation and estimation of stochastic frontier production function models", $J$. Econometrics, vol. 6, pp. 21-37, 1977.

[31] W. Meeusen, and J. van den Broeck, "Efficiency estimation from cobb-douglas production functions with composed error", Int. Econ. Rev., vol. 18, pp. 435-444, 1977.

[32] G. E. Battese, and T. J. Coelli, "A model for technical inefficiency effects in a stochastic frontier production function for panel data", Empir. Econ., vol. 20, pp. 325-332, 1995.

[33] L.J. Mester, "A study of bank efficiency taking into account riskpreferences", J. Bank. Finance, vol. 20, pp. 1025-1045, 1996.

[34] A.S. Cebenoyan, E.S. Cooperman, C.A. Register, and S. C. Hudgins, "The relative efficiency of stock versus mutual S\&LS: a stochastic cost frontier approach", J. Finan. Serv. Res., vol. 7, pp. 151170, 1993.

[35] L. Allen, and A. Rai, "Operational efficiency in banking: an international comparison", J. Bank. Finance, vol. 20, pp. 655-672, 1996.

[36] Y. Altunbas, M-H Liu, P. Molyneux, and R. Seth, "Efficiency and risk in Japanese banking", J. Bank. Finance, vol. 24, pp. 1605$1628,2000$.

[37] The Taiwan Stock Exchange Inc., Market Observation Post System, Retrieved from http://mops.twse.com.tw/, 2011.

[38] Directorate-General of Budget, Accounting and Statistics, Executive Yuan, Taiwan, Available at: http://www.dgbas.gov.tw/, 2011.

(C) Dzeng and Wu; Licensee Bentham Open.

This is an open access article licensed under the terms of the Creative Commons Attribution Non-Commercial License (http://creativecommons.org/licenses/by-nc/3.0/) which permits unrestricted, non-commercial use, distribution and reproduction in any medium, provided the work is properly cited. 